\title{
Perspicacity, Sagacity \& Mentorship: A Management Model for Strategic Leadership Success in Faculty Senate Governance
}

\author{
Marcia M. Hardy \\ Northwestern State University of Louisiana \\ Danny Upshaw \\ Northwestern State University of Louisiana \\ John Williams \\ Northwestern State University of Louisiana
}

Faculty senators participate in shared governance and play an important role in higher education's policy-making. This paper presents a theoretical framework for promoting governance success. It highlights three potential success factors: perspicacity, sagacity, and mentorship. A management model supporting success in faculty senate governance should also consider including advisory board involvement and active participation in mentor leadership training. The model was constructed to emphasize the importance of effective faculty senator leadership development in practical terms.

Keywords: Management, Management Model, Faculty, Faculty Senate, Senators, Governance, Mentorship, Senate, Training, Advisory Board, Faculty Training, Personality Testing, Executive Board, Board Membership, Traits

\section{INTRODUCTION}

University and college faculty senators across the country are given the responsibility of shared governance and play an important role in decision-making. As part of their responsibilities, senators are called upon to provide guidance for policy-making in higher education's institutional matters which can have long term impact on students, faculty, community stakeholders and university systems. In February 2011, in a report entitled Academic Freedom, Shared Governance, and the First Amendment after Garcetti v. Ceballos presented by Rachel B. Levinson, Senior Counsel for the American Association of University Professors at the $31^{\text {st }}$ Annual National Conference on Law and Higher Education, the report addressed several issues associated with shared governance and the roles and responsibilities of faculty committees. It is pointed out in this report that a committee chaired in 2009 by Robert O'Neil, on the subject of academic freedom and First Amendment rights stated:

"Faculty involvement in institutional decision-making helps ensure campus-wide "buy-in," with respect to both the decision-making process and the decision itself. Decisions reached without faculty 
input may be insufficiently attentive to core academic values, may not reflect the realities on campus, or may simply be difficult to execute. Moreover, once a decision is made and implementation begun, ongoing faculty involvement and cooperation are essential. Without the freedom to engage deeply in that decision-making and implementation process - including the freedom to voice disagreement over the direction of a policy or the method of execution - the entire academic community will be ill served."

Although faculty involvement and agreement in higher education decision making and policy setting is an important aspect of participation in university systems, there is little research to indicate faculty leadership preparation and governance training is provided to senators in advance of participating in this important leadership role. This paper presents a strategic leadership model for consideration in promoting faculty senator success in the governance process. Given the paucity of research on the predictors of faculty senator leadership success, it is worth the effort to explore the value of lesser known leadership characteristics which could foster faculty senator success.

\section{Perspicacity and Sagacity}

In 17th century Europe René Descartes devised rules for "clear thinking" in his work entitled "Rules for the Direction of the Mind" ( Regulæ ad directionem ingenii) or rules for the direction of natural intelligence. Descartes suggests intelligence consists of two talents. The first aptitude would be perspicacity, that is, an aptitude which provides an "understanding or intuition of distinct detail" (en.wikipedia.org/wiki/Perspicacity). Perspicacity is defined as a keenness of mental perception and understanding; having the quality of a penetrating discernment, or keen vision. It is an "acuteness of perception, discernment or understanding" (www.thefreedictionary.com/perspicacity). It is a "clarity of vision or intellect which provides a deep understanding and insight" (en.wikipedia.org/wiki/Perspicacity).

The second facility is sagacity. Sagacity is defined as a characteristic which enables "reasoning about the details in order to make deductions" (en.wikipedia.org/wiki/Perspicacity). It is the quality of "acuteness of mental discernment and soundness of judgment" (dictionary.com/sagacity). Several related words identified in the dictionary include enlightenment, knowledge, insight, prudence, understanding, discernment, practicality, experience, judgement, discrimination and comprehension.

By employing these two abilities, perspicacity and sagacity, which embody clarity of vision, practicality, experience, discrimination and comprehension, a sharp-sighted academic will demonstrate a deeper understanding or vision of the issues. Senators collectively engaged in perspicacity, will come to see and recognize the realities of the situational issues. By employing sagacity, thoughtful reasoning for making deductions, senators will begin formulating and implementing fair and equitable solutions and recommendations for action to resolve the problems, the difficulties, and the identified issues. Faculty senators will work together to discover well-founded rulings to be presented to university policy-makers for consideration. This is our ideal faculty senate in action.

Successful organizational management encourages courageous academic brothers and sisters to dive deep into the simple details and facts, employing perspicacity and devising proposed solutions to problems that face our university and university colleagues. If leaders on both sides of a contentious issue employ perspicacity, "a keenness of mental perception and understanding; penetrating discernment, or keen vision" and if all parties perform their due diligence in ferreting out the details surrounding the issue, sound judgement and viable recommendations may prevail and proceed forward for review and discussion by administrative decision-makers.

Within the faculty senate it is the job and responsibility of the leadership, the faculty senate executive board and president to guide this process. It is the executive board's responsibility to provide an environment which nurtures this skill and leadership quality in each of its faculty senate members. Perspicacious faculty senators and leaders make informed decisions and present sound, fully vetted recommendations to university administrators that will be respected. This could be a foundational quality for successful faculty senate actions and is invisibly directed by the faculty senate president and his or her executive board. 


\section{Know Thyself and the Facts}

What perspicacity is not is being the quality of obtuseness that is, ignorance. Successful organizational behavior implies knowing yourself and the facts. In order to lead effectively, leaders should know who they are. Successful organizational leaders identify their strengths and weaknesses. Successful leaders may ask themselves important questions such as, "How do I work with others? What is my best leadership quality? Do I effectively communicate and receive information?" Leaders should recognize what personality tools they bring to the senate floor discussion and decision-making process. Importantly they should invite other colleagues to join in the decision-making. There are many personality tests, tools and consulting firms, self-help manuals, available to assist a faculty member in identifying their true self. Profile inventories such as Myers-Briggs (MBTI), Emergenetics, Leadership 360, Leadership Practices Inventory (LPI) Assessments, John Maxwell Leadership Assessment, DISC profile (dominance, influence, steadiness and compliance, Gallup's Strengthfinder, etc., are available to prepare senators to understand themselves better. These profiles and assessments may give the faculty member a distinctive look into identifying their individual skills and talents and assist them in honing these skills. Inventories are available to help identify unique roles and contributions which can be made as a member of a team such as a university faculty senate.

There are major issues impacting the state university systems, budgetary concerns, conflicted major players, student concerns, academic concerns, and confounding difficulties that alter the rules of the game and the decision-making playing field. These may permanently alter the landscape of higher education and negatively or positively impact a way of living and perhaps livelihoods. To be effective, a faculty senator should be an informed leader even as the landscape ebbs and flows.

\section{Mentorship}

Research indicates a growing interest in experienced corporate employees mentoring co-workers in the workplace setting. Successful organizations often employ the practice of mentorship. Following a study conducted by Billett (2003), the author indicated "mentors noted the efficacy of guiding learning in the workplace". Haines defined mentorship as a deliberate activity whereby mentors perform their obligations and responsibilities with mindful effort in a supportive relationship with the goal of cultivating the protege's aptitude. Mentors offer support, guidance and exemplary role modeling, informally and formally, to assist the protégé' in being able to perform the tasks and acquire the necessary skills to perform the required tasks successfully.

The importance of formal mentorship programs to improve performance has also been recognized. In 2013, Hester and Setzer published an article entitled, Mentoring: Adding Value to Organizational Culture. In summary, the characteristics identified by the authors as most often evidenced with being a mentor suggested leaders are "cognizant of their strengths, weaknesses, and limitations; able to articulate and assess their performance; voluntarily work to build the communication and ethical skills of a protégé; encourage protégés to openly discuss problems and take responsibility for the outcomes; communicate a belief in the ability of protégés; consider mentoring as ethical as well an organizational commitment and are willing to invest his/her knowledge and experience in the protégé".

Leadership training and mentoring have been an integral component of leader preparation for decades. Mentoring and "shadowing" in the corporate world is a routine matter of course. Supervisor training and on-the-job experiential training are an integral part of the business world's preparation for corporate leaders, project managers and supervisors. The mentor or training approach to shared governance in the academic environment has been underutilized and should be a requirement in the academic world of leadership and university corporate responsibility.

Faculty Leadership Institutes should become a cornerstone of academic senate governance training around the country. These institutes should be being created to assist new faculty senate leaders in navigating the intricacies of shared governance. Veteran faculty senators and faculty senate leaders should come together to share tools and experiences to prepare new leaders to successfully perform their obligations and responsibilities leading the senate. Experienced faculty senators who have provided well thought-out policy advice, proposed initiatives, and recommendations in their university environments 
should partner with inexperienced, emerging faculty members preparing them to provide the required leadership and guidance.

A leadership institute training program was recently inaugurated by the University of Louisiana System under the leadership and guidance of President Dr. Jim Henderson. This was an important first step forward for the nine-member universities of University of Louisiana System in developing prepared leaders. The Management and Leadership Institute for the Universities of Louisiana is a two-semester program for "mid-career faculty and staff who aspire to academic, professional or administrative leadership roles".

During the course of the program, institute participants are immersed in "a program designed to maximize their effectiveness in management roles. They will gain a deeper understanding for effective leadership in higher education and learn how to develop diverse, high-performing teams; manage and implement change; analyze financial, student and market data; and identify and seize opportunities in the increasingly competitive market driven environment of higher education." It includes group projects and job shadowing and mentoring". The goals of the institute participants as outlined on the University of Louisiana System website are to: "gain familiarity with contemporary challenges facing academic and administrative leaders; deepen understanding of fundamental perspectives and concepts of leadership as they apply in higher education; enhance personal and professional leadership competencies; advance the University of Louisiana System by leading a system-based group project from conception through completion; increase understanding of important dimensions of higher education administration, including organizational structure and mission, governance, finance and budgeting, legal and regulatory issues, diversity and ethics". These program principles should also be integral ingredients in any faculty senate leadership training institute or program.

Additionally, a Past Presidents' Advisory Board is also a relevant body of expertise that is often available to corporate leaders. An effective advisory board often provides informed guidance and functions as a partner or collaborator providing significant experience and offering support in the corporate governance arena. As Reiter (2003) suggests, "Advisory boards provide safe harbours for executives who may be able to test -drive options before they are forced to be more definitive and assertive before a board of directors, which assesses the CEO and establishes his or her compensation. A CEO may feel more comfortable expressing partially defined or tentative views before a group whose sole purpose is to provide advice. For the same reason, an advisory board may also serve as an instrument of change, both as a sounding board for senior executives".

\section{CONCLUSION}

Leaders are cultivated. Leaders are nurtured and supported. In an effort to successfully analyze governmental and policy operations, budgetary issues and concerns, and deal with the emerging difficult issues of higher education, a management model for strategic leadership success in faculty senate governance should be constructed to include organizational management practices. These management practices should include the regular exercise of perspicacity and sagacity as practical measures of organizational management.

Faculty senators should be actively encouraged to explore organizational behavior as demonstrated in personal-professional behavioral terms. Senators should be supported in identifying and developing individual senators' leadership personality profiles and skills, emboldened to probe and inquire into their individual and corporate personalities, gifts, and skills as recognized through the use of supported behavioral measurement tools.

And lastly, a management model supporting success in faculty senate governance should consider including advisory board involvement and active participation in mentor leadership training. These structures should be included as a necessary step on the practical path toward success in undertaking the opportunities and responsibilities experienced as members of the university's faculty senate leadership. 


\section{REFERENCES}

Bickel J, Lark V. (2000). Encouraging the advancement of women: mentorship is key. JAMA, 283(5),671.

Billett, S. (2003). Workplace mentors: demands and benefits. Journal of Workplace Learning, 15(3), 105113.

Dictionary.com/browse/sagacity.

Drucker P. (1999). Managing oneself. Harvard Business Review,77(2), 64- 74,185.

Haines ST. (2003). The mentor-protege' relationship. Am J Pharm Educ., 67(3), Article 82.

Hester, J. P., \& Setzer, R. (2013). Mentoring: Adding Value to Organizational Culture. The Journal of Values-Based Leadership, 6(1), Article 4.

Irby, B. J., Lynch, J., Boswell, J., \& Hewitt, K. K. (2017). Mentoring as professional development. Mentoring \& Tutoring: Partnership in Learning, 25(1).

Jackevicius, C. A., Le, J, Nazer, L., Hess, K, Wang, J., \& Law, A. (2014). Faculty Development: A Formal Mentorship Program for Faculty Development. American Journal of Pharmaceutical Education, 7 (5), Article 100.

Levinson, R.B. (n.d.). Academic Freedom, Shared Governance, and the First Amendment after Garcetti v. Ceballos. Retrieved from www.aaup.org/NR/rdonlyres/4126513-1194-4317-8123459BD9F30A6D/0/Stetson2011AcadFreedomFirstAmdmtoutline.pdf.

Management and Leadership Institute. (n.d.). Retrieved from ULSystem.edu/management-and-leadershipinstitute/

Perspicacity. (n.d.). Retrieved from https://www.thefreedictionary.com/perspicacity

Perspicacity. (n.d.). Retrieved from Wikipedia.org/wiki/Perspicacity.

Reiter, B. (2003). The Role and Value of an Effective Advisory Board. Ivey business Journal. September-October, Category: Governance. 